University of Montana

ScholarWorks at University of Montana

$1-1996$

\title{
Effects of Regional Origin and Genotype on Intraspecific Root Communication in the Desert Shrub Ambrosia Dumosa (Asteraceae)
}

\author{
Bruce E. Mahall \\ Ragan M. Callaway \\ University of Montana - Missoula, Ray.Callaway@mso.umt.edu
}

Follow this and additional works at: https://scholarworks.umt.edu/biosci_pubs

Part of the Biology Commons

Let us know how access to this document benefits you.

\section{Recommended Citation}

Mahall, Bruce E. and Callaway, Ragan M., "Effects of Regional Origin and Genotype on Intraspecific Root Communication in the Desert Shrub Ambrosia Dumosa (Asteraceae)" (1996). Biological Sciences Faculty Publications. 290.

https://scholarworks.umt.edu/biosci_pubs/290

This Article is brought to you for free and open access by the Biological Sciences at ScholarWorks at University of Montana. It has been accepted for inclusion in Biological Sciences Faculty Publications by an authorized administrator of ScholarWorks at University of Montana. For more information, please contact scholarworks@mso.umt.edu. 


\title{
EFFECTS OF REGIONAL ORIGIN AND GENOTYPE ON INTRASPECIFIC ROOT COMMUNICATION IN THE DESERT SHRUB Ambrosia DUMosa (ASTERACEAE) ${ }^{1}$
}

\author{
Bruce E. Mahall ${ }^{2}$ and Ragan M. Callaway
}

\begin{abstract}
Department of Ecology, Evolution and Marine Biology, University of California, Santa Barbara, California 93106; and Division of Biological Sciences, University of Montana, Missoula, Montana 59812
\end{abstract}

\begin{abstract}
Previous work has shown that the contact inhibition that occurs among roots of Ambrosia dumosa shrubs has a self/ nonself recognition capability. In the current study, we investigated some of the geographic and genotypic dimensions of this recognition capability by using root observation chambers to observe the effects of encounters of individual roots on root elongation rates. We measured such effects in encounters between roots of plants from the same region and compared these to effects in encounters between roots of plants from two different regions. We also measured effects of encounters between roots of plants from the same clones and compared these to effects of encounters of roots of plants from different clones. Roots of plants from the same region (population) showed the usual "nonself" precipitous decline in elongation rates following contact, but when roots of plants from different regions contacted each other, elongation rates continued unchanged. When roots of separate plants from the same clone contacted each other, the same "nonself" precipitous decline in elongation rates as seen in encounters between roots of plants of different clones from the same region occurred. Meanwhile, in these same experiments "self" contacts between sister roots connected to the same plants resulted in no changes in elongation rates. Thus, differences between individuals from two geographically separate populations of Ambrosia dumosa may be sufficient to thwart the "nonself," population-level recognition of similarity apparently necessary for contact inhibition. Furthermore, the "self" recognition mechanism, which precludes contact inhibition between two roots on the same plant, appears to be physiological rather than genetic in nature.
\end{abstract}

Key words: Ambrosia; communication; community structure; desert shrubs; interplant signalling; root contact inhibition; root interactions; self-nonself recognition.

Belowground competition for limiting resources is dependent upon spatial proximity of primary roots on the scale of the dimensions of water and nutrient depletion zones around roots. Since these zones are usually less than a few millimetres in diameter (Clarkson, 1985; Caldwell and Richards, 1986), the spatial proximity and, therefore, the opportunity for competition among two or more plants' root systems could be strongly affected by "communications" among individual roots that affect root elongation rates.

Such communications among roots of the desert shrub Ambrosia dumosa Payne (Asteraceae) were discovered (Mahall and Callaway, 1991) during an attempt to understand the absence of competitive interactions among clumped Ambrosia shrubs growing in the Mojave Desert (Fonteyn and Mahall, 1978, 1981). Using chambers in which it was possible to observe responses of individual roots to each other in the laboratory, Mahall and Callaway (1991) found that Ambrosia roots inhibited elongation of roots on other Ambrosia plants only, and only after actual contact. Sister roots on the same plant did

\footnotetext{
${ }^{1}$ Manuscript received 17 January 1995; revision accepted 8 June 1995.

The authors thank Allen Steward-Oaten for his advice on statistics, John Bleck for his kind and helpful assistance in the UCSB Greenhouse Facilities; the University of Nevada, Reno, for the use of their greenhouse facilities; Michael Christianson, Curtis Clark, and C. H. Muller for helpful suggestions and encouragement; Jochen Schenk, Jason Hamilton, and two reviewers for $A J B$ for their helpful comments on the manuscript; and the UCSB Academic Senate and especially the Andrew W. Mellon Foundation for the financial support of this research.

${ }^{2}$ Author for correspondence.
}

not inhibit each other following contact, nor were Larrea tridentata Cov. (Zygophyllaceae) roots affected by contact with Ambrosia roots. These results suggested the existence of an intraspecific, self/nonself recognizing communication system mediated by contact. Further work (Mahall and Callaway, 1992) supported the hypothesized contact requirement by showing that activated carbon mixed in the root medium had no effect on Ambrosia root communications. It was also observed that the nonself recognition capability is not perfect, since in one out of 17 Ambrosia test-target pairs the test plant roots were not inhibited by contact with the target plant roots.

This observation suggested limits to the self/nonself recognition system might be displayed over ranges of geographic or genotypic variation. The purpose of the work reported here was to explore the geographic and genotypic dimensions of the self/nonself recognition capability of Ambrosia dumosa roots by comparing the effects of encounters between roots of plants from the same region (population) with such effects between roots of plants from different regions, and by comparing the effects of encounters between roots of plants of the same genotype with such effects between roots of plants with different genotypes, respectively. We have done this by measuring interactions among roots of plants grown from seeds or cloned from mature plants collected from two desert sites $\approx 145 \mathrm{~km}$ apart, one near Desert Center, California, and the second near Yuma, Arizona.

\section{MATERIALS AND METHODS}

Plant materials-Plants for the intra- and interregional experiments were grown from seeds collected from inflorescences on plants during 
May 1991, from a site (33 $44^{\prime}$ lat. and $115^{\circ} 28^{\prime}$ long.) near Eagle Mountain Road near Desert Center, California, and from another site $\approx 10 \mathrm{~km}$ north of Yuma along Route 95 ( $32^{\circ} 50^{\prime}$ lat. and $114^{\circ} 22^{\prime}$ long.). Since each collection site was relatively small ( $<200 \mathrm{~m}$ in diameter), a single population was presumably sampled in each region. In the laboratory these seeds were germinated in wet sand in flats before being transplanted into the root chambers.

For the intra- and intergenotypic experiments whole, mature shrubs were collected from the same Desert Center and Yuma sites during June 1992. The shoots of these plants were heavily pruned in the field, and then their main roots were dug up. The plants were carried in large, black, plastic bags back to the laboratory, where they were broken apart by hand into pieces of main stems with connected roots (see Jones and Lord, 1982) to produce clones of genetically identical individuals from single plants. These clones were carefully labeled and planted in fine, wet sand in pots. The cloned individuals that survived to produce new shoots, leaves, and roots were transplanted into the root chambers.

Root chamber experiments-As in our previous studies (Mahall and Callaway, 1991, 1992), plants for the root interaction experiments were grown in flat, rectangular chambers $(20.5 \times 12.5 \times 2 \mathrm{~cm}$, inside dimensions), constructed of opaque polyvinyl chloride plastic (PVC), filled with fine sand ("Lapis Lustre," sieve size \#60 [grain diameter = 0.2-0.7 mm], RMC Lonestar, Pleasanton, CA) and oriented at a $45^{\circ}$ angle, so that the positively geotropic roots would grow down along the Plexiglas viewing windows sloping at $45^{\circ}$ and covered with removable opaque shutters on the lower sides of the chambers. After a period of establishment and growth, pairs of chambers were connected together along edges opened by the removal of partitions, so that roots of a "test" plant would grow past the bottom edge of its test chamber through the side edge of the "target" chamber, which was rotated by $90^{\circ}$ to make the connection. Roots of test plants encountered the rhizospheres of target plants in the target chambers. Elongation rates of all test plant roots visible and traceable through the viewing windows were calculated from measurements of length (to an accuracy of 0.1 $\mathrm{mm}$ ) made at recorded times every $2 \mathrm{~d}$. These measurements were begun days before the test and target chambers were connected. At the time of each measurement test roots were scored as to whether or not they had contacted target roots and/or other test roots during the previous interim between measurements. Contact between test roots and other roots was judged to have occurred when the root tip of a test plant had touched any part of another root. The sand in the chambers was kept continually moist and flushed with one-eighth strength Hoagland's solution every 8-10 d. Both the regional and genotypic experiments were conducted in bright, warm greenhouses at the University of California, Santa Barbara, during June, July, and August 1991 and at the University of Nevada, Reno, during July and August 1992, respectively.

In the intraregional experiments, root growth of test Desert Center seedlings (originating from seed collected from the Desert Center site) was directed at roots of target Desert Center seedlings, and root growth of test Yuma seedlings (originating from seed collected from the Yuma site) was directed at roots of target Yuma seedlings. The interregional experiments were conducted contemporaneously, and in them root growth of test Desert Center seedlings was directed at roots of target Yuma seedlings, and root growth of test Yuma seedlings was directed at roots of target Desert Center seedlings.

Clones derived from mature plants collected from both the Desert Center and Yuma site were used in both the Same Clone (intragenotypic) Experiments and the Different Clone (intergenotypic) Experiments. In the Same Clone Experiments root growth of test plants was directed at roots of target plants from the same clone. In the Different Clone Experiments root growth of test plants was directed at roots of target plants from a different clone but originating from the same field site.

Statistical estimates and tests applied here were the same as those applied previously (Mahall and Callaway, 1991, 1992). Variances in root elongation rate among plants $\left(\mathrm{S}_{\mathrm{P}}{ }^{2}\right)$ and among roots $\left(\mathrm{S}_{\mathrm{R}}{ }^{2}\right)$ on a plant were estimated in a single-classification ANOVA with unequal sample sizes (Sokal and Rohlf, 1981, p. 216). Root elongation means for treatments and dates were estimated using the weighted averages of the plant means (root elongation rates averaged per test plant $\times$ weighting factor). The weighting factors are $W_{i} / W$, where $W_{i}=1 /\left(\mathrm{S}_{\mathrm{P}}{ }^{2}+\left[\mathrm{S}_{\mathrm{R}}{ }^{2} / n_{i}\right]\right), n_{i}=$ number of roots measured on plant $i$, and $W=\Sigma W_{i}$. Standard errors of these estimates of the means $=1 / \sqrt{W}$. In addition, a repeated-measures ANOVA, based on $N=$ number of test plants, with root elongation rates averaged per test plant, was used to test for differences among treatments using data from all days presented in the figures, including those before contact.

\section{RESULTS}

When roots of test plants grown from seeds from the Desert Center site contacted roots of target plants of the same origin, the usual (Mahall and Callaway, 1991, 1992), precipitous declines in elongation rates occurred following contact (Fig. 1). Meanwhile, roots of these same test plants that did not contact target plant roots continued to elongate at unabated rates. However, when roots of Desert Center test plants contacted roots of Yuma target plants they showed no reaction in elongation rates. They continued to elongate at rates insignificantly different from their initial elongation rates and from the elongation rates of their sister roots on the same test plants that did not contact target roots.

Similarly, when roots of test plants grown from seeds from the Yuma site contacted roots of target plants of the same origin, precipitous declines in elongation rates of these test plant roots occurred, while other roots on the same test plants, that did not contact target roots, continued elongating with no changes in rates (Fig. 2). When Yuma test plant roots contacted target roots on Desert Center plants, however, no change in elongation rates of test roots occurred, and they continued to elongate at rates insignificantly different from those of their sister test roots that did not contact any target roots.

When roots of test plants cloned from plants collected from either Desert Center or Yuma contacted roots of target plants from the same clone, their elongation rates declined precipitously (Fig. 3, Same Clone Experiments, Inter-plant contact). These responses were indistinguishable from those of test plant roots that contacted target roots of plants from different clones but the same region (Fig. 3, Different Clone Experiments, Inter-plant contact) or from those reported for contact in the other intraregional experiments with seedlings (Figs. 1, 2). Meanwhile, on the same cloned test plants, roots that contacted only sister roots connected to the same test plants (Fig. 3 , Intra-plant contact) showed no significant change in elongation rates during these experiments, and their elongation rates were not significantly different from those of other roots on these same plants that did not contact any roots at all (Fig. 3, Non-contact). Results from both Desert Center and Yuma plants are combined in Fig. 3, since there were no significant regional differences in the responses found in these experiments.

\section{DISCUSSION}

Some important characteristics of the recognition capability of the root communication system in Ambrosia 


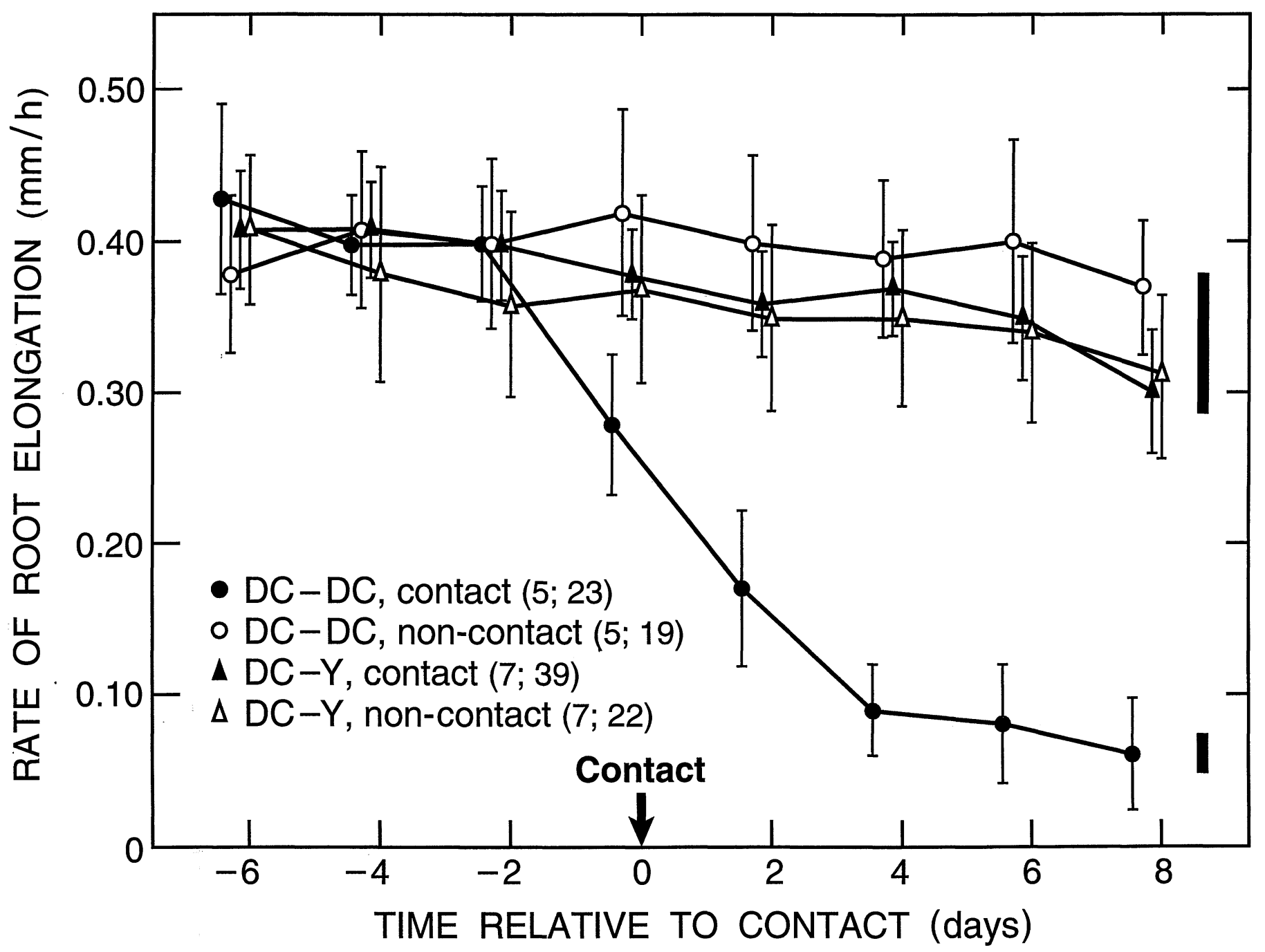

Fig. 1. Rates of elongation of test roots of Ambrosia seedlings grown from Desert Center seed with (contact) or without contact (non-contact) with any other root and before and after contact (arrow at day 0) with target Ambrosia roots on seedlings grown from Desert Center (DC) or Yuma (Y) seed. Elongation rates of all test roots were standardized in time by aligning at day 0 the days on which their contact with a target root was first observed. Since observations were made every $2 \mathrm{~d}$, at day 0 all contact roots had first touched another root some time during the 2-d interim between measurements immediately preceding day 0 . Day 0 for non-contact roots was taken to be the average day of contact for sister contact roots of approximately the same age on the same plant. The numbers in parentheses represent the number of test plants (i.e., the number of testplant-target-plant pairs) and the total number of roots measured. Measurements were made nearly simultaneously on each day, but the symbols are offset in the figure for clarity. Non-contact roots were on the same test plants as contact roots within target types. Error bars indicate 2 SE on either side of the means. Descriptions of statistical analyses are present in Materials and Methods. Treatments whose final means do not share a bar at the right-hand side of the figure were significantly different as determined by repeated-measures ANOVAs $(P<0.05)$.

dumosa were discerned by an examination of the effects of regional origin and genotype on interroot interactions.

The data in Figs. 1, 2 indicate that differences between individuals from two geographically separate populations of Ambrosia dumosa may be sufficient to thwart the nonself, population specific recognition apparently necessary for the contact inhibition that normally occurs between individuals from the same population. In fact, the absence of a response between individuals in these intraspecific, interregional pairs of plants was not perceptively different from the lack of an interspecific response of test Larrea roots to target Ambrosia roots (Mahall and Callaway, 1991). Currently, we do not know the nature or degree of the differences responsible for the lack of intraspecific contact inhibition in Ambrosia. Such differences could be related to possible differences in chromosome numbers between the Desert Center and Yuma populations. Diploids, tetraploids, hexaploids and possibly octaploids of Ambrosia dumosa may be found in these regions (Payne, 1964; Raven et al., 1968). Ploidy levels have been shown to correspond with differences in secondary chemistry (Geissman and Matsueda, 1968; Payne, Scora, and Kunamoto, 1972; Seaman and Mabry, 1979), and possibly morphology and phenology (Raven et al., 1968).

While the origin of the seeds used in the 17 experiments conducted previously (Mahall and Callaway, 1991, 1992) was unknown, in the experiments reported here we knew the precise regional origin of the seeds, and contact inhibition occurred between roots of plants of all intrapopulational test-target pairs. The prevalence of contact 


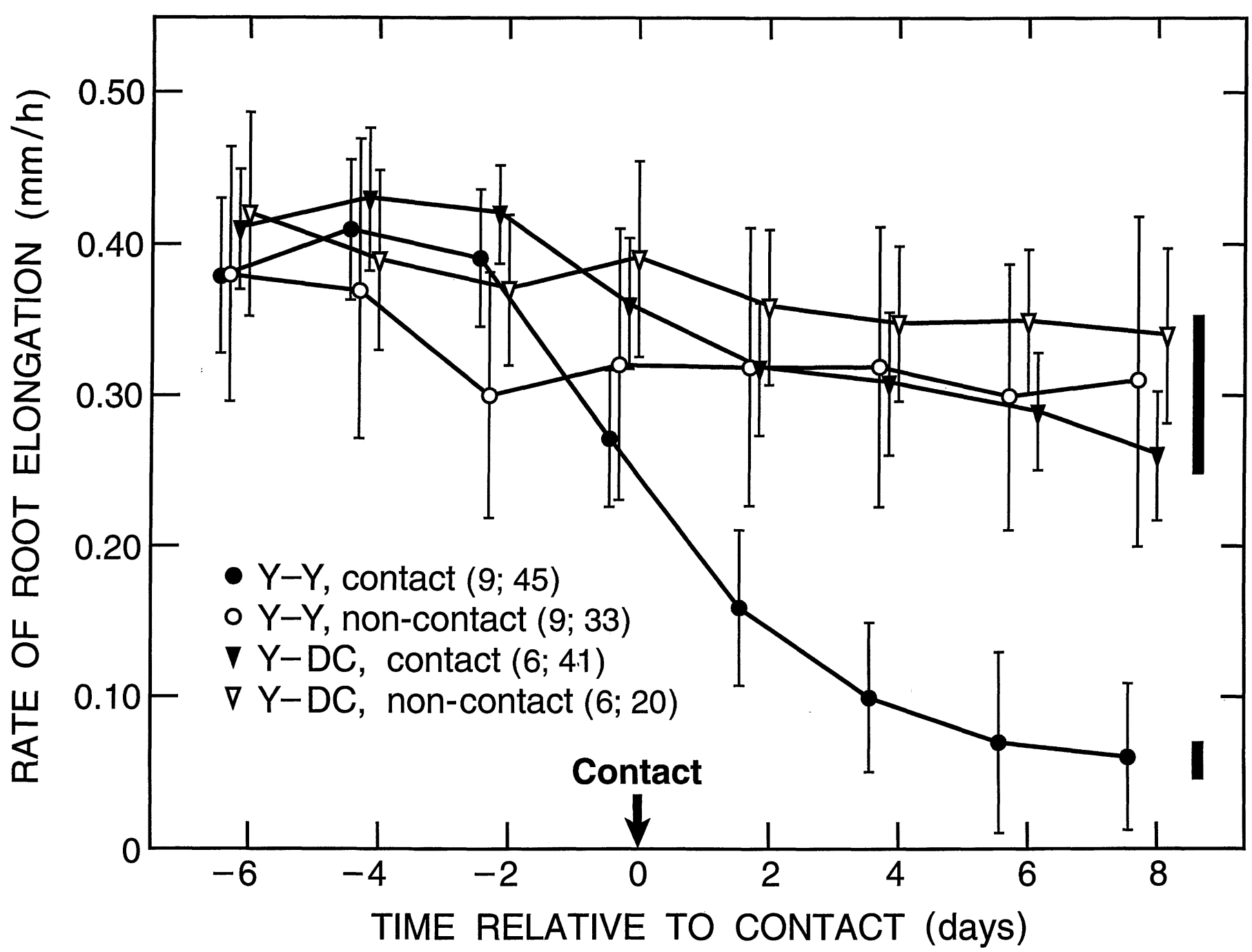

Fig. 2. Rates of elongation of test roots of Ambrosia seedlings grown from Yuma seed with (contact) or without contact (non-contact) with any other root and before and after contact (arrow at day 0) with target Ambrosia roots on seedlings grown from Yuma (Y) or Desert Center (DC) seed. See Fig. 1 legend for details.

inhibition in root interactions among plants from the same population suggests genetic similarity does not pose an exemption to and may be a prerequisite for root contact inhibition. Since neighboring shrubs in the field are likely to be genetically most similar, this finding permits the possibility, postulated by Mahall and Callaway (1991, 1992), that the Ambrosia contact inhibition mechanism could function as a detection and avoidance system that reduces belowground competition for limiting resources among neighboring and perhaps closely related shrubs. This would occur when ample soil volumes are available, and those roots of neighboring plants that touch each other decline in growth, while other, non-contact roots continue to grow unimpeded into unoccupied soil volumes. The finding of root contact inhibition among genetically similar plants also supports the prediction of intense interference due to resource competition plus contact inhibition among sibling seedlings during establishment in a dense stand, where ample soil volumes for all plants are not available (Mahall and Callaway, 1992). The ecological importance of the absence of contact inhibition between plants from different regions would only be as great as the opportunity for such plants to encounter each other in the field. The extent of this opportunity is currently unmeasured.

The results of our experiments with clones of Ambrosia plants (Fig. 3) show clearly that, like genetic similarity, genetic identity of two interacting plants does not pose an exemption to contact inhibition. Genetically identical roots on separate plants did inhibit each other. This finding is consistent with and extends our findings regarding regional origin and presumed genetic similarity to the condition of ultimate genetic similarity-genetic identity. But, mechanistically, this finding indicates that genetic identity cannot explain why two sister roots on the same plant do not inhibit each other, as consistently demonstrated in these experiments (Fig. 3) and in all others we have conducted with Ambrosia dumosa (Mahall and Callaway, 1991, 1992). Thus, while nonself, population specific recognition, as evidenced by contact inhibition, appears to require a degree of genetic similarity, self recognition in this system appears not to be a simple 


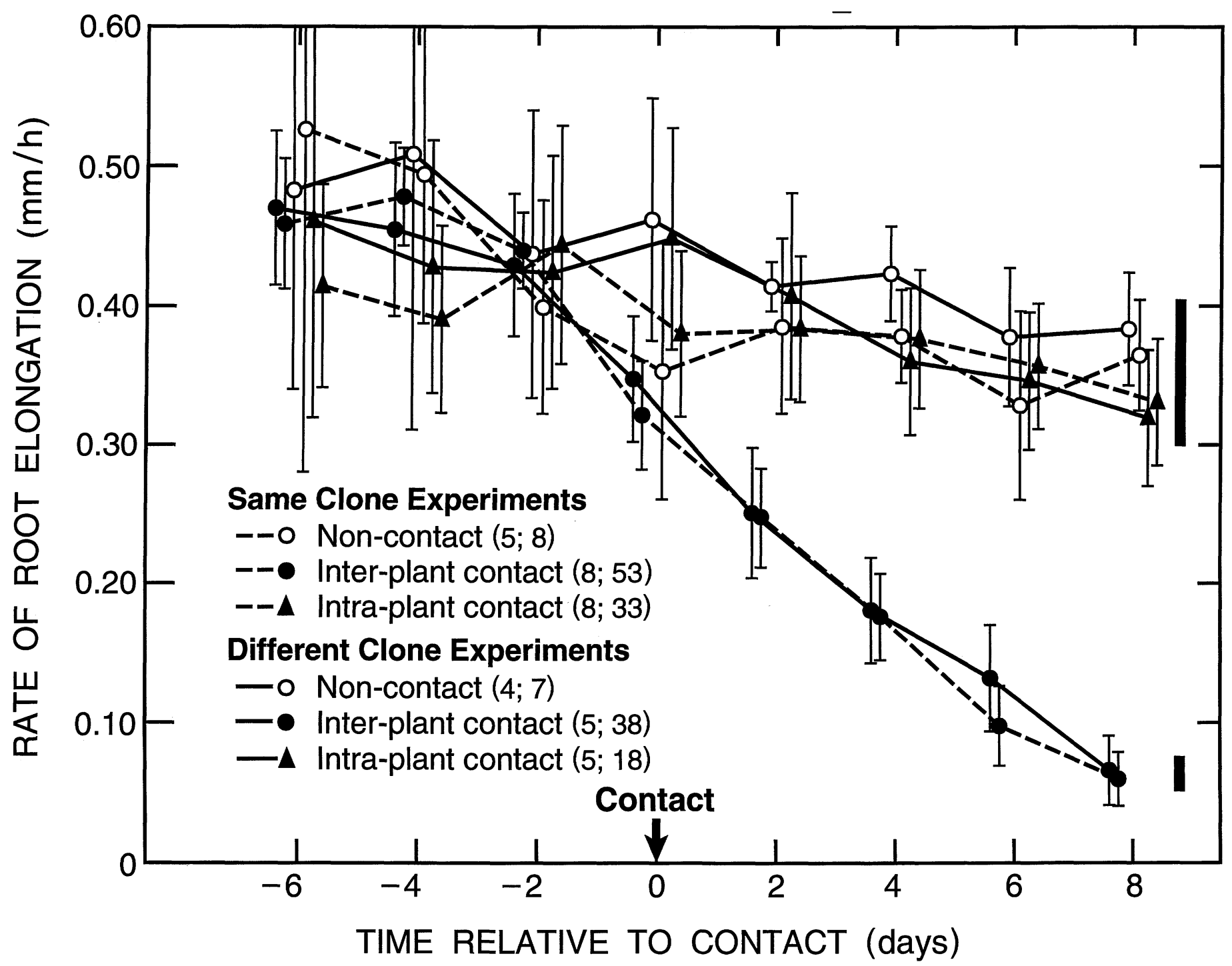

Fig. 3. Rates of elongation of test roots of clones of mature Ambrosia plants collected from Desert Center or Yuma and grown at target plants from the same region in eight experiments with test and target plants from the same clones (Same Clone Experiments) and in five experiments with test and target plants from different clones (Different Clone Experiments). Results from roots without contact (Non-contact) with any other root and before and after contact (arrow at day 0) with roots of target plants (Inter-plant contact) or with other (sister) roots on the same test plant (Intra-plant contact) are reported for both the Same Clone and the Different Clone Experiments. In three Same Clone Experiments and one Different Clone Experiment non-contact roots did not remain non-contact long enough for a complete series of measurements. See Fig. 1 for further details.

function of recognition of genetic identity. The data presented here suggest the mechanism that precludes contact inhibition when two roots on the same plant touch each other may be physiological rather than genetic in nature.

Thus, our work suggests the root communication mechanism in Ambrosia dumosa includes three components: (1) a recognition system that is capable of making population level distinctions in a time span of less than a day; (2) an inhibition system that does not involve exudation of readily diffusible, organic chemicals adsorbable by activated carbon (Mahall and Callaway, 1992), and that is capable of reducing rates of elongation of contacted roots by up to $80 \%$ in $<1$ wk; (3) a self-recognition system capable of distinguishing between actual, physiological self and genetic identity. Additionally, physical contact between roots appears to be a prereq- uisite for this mechanism to come into play. Future research is needed to clarify further the geographic and genotypic dimensions of the population specific recognition system suggested to exist by the current results and to elucidate the biochemical and/or biophysical characteristics of the whole communication mechanism. These characteristics are entirely unknown at this time.

The possibility that root communications in Ambrosia dumosa may provide a mechanism by which closely related individuals can partition belowground resources and avoid direct resource competition remains to be tested. The degree of occurrence of similar communication mechanisms among other taxa also remains to be investigated. If root communications do function in the way suggested here, and if forms of such communication mechanisms commonly exist in other taxa, current views 
regarding the mechanisms by which plant-plant interactions influence community structure may require considerable alteration. Moreover, the degree of sophistication of communication revealed by our investigations of the Ambrosia dumosa system suggests the study of plant behavior below ground may be on the threshold of delving into a whole new level of complexity in which terms like "competition" and "allelopathy" will be seen as gross oversimplifications.

\section{LITERATURE CITED}

CAldwell, M. M., AND J. H. Richards. 1986. Competing root systems: morphology and models of absorption. In T. J. Givnish [eds.], On the economy of plant form and function, 251-273. Cambridge University Press, Cambridge.

Clarkson, D. T. 1985. Factors affecting mineral nutrient acquisition by plants. Annual Review of Plant Physiology 36: 77-115.

Fonteyn, P. J., AND B. E. Mahall. 1978. Competition among desert perennials. Nature 275: 544-545.

, AND B. E. MAHALl. 1981. An experimental analysis of structure in a desert plant community. Journal of Ecology 69: 883-896.
Geissman, T. A., AND S. Matsueda. 1968. Sesquiterpene lactones. Constituents of diploid and polyploid Ambrosia dumosa Gray. Phytochemistry 7: 1613-1621.

JONES, C. S., AND E. M. LORD. 1982. The development of split axes in Ambrosia dumosa (Gray) Payne (Asteraceae). Botanical Gazette 143: 446-453.

Mahall, B. E., and R. M. Callaway. 1991. Root communication among desert shrubs. Proceedings of the National Academy of Sciences, USA 88: 874-876.

, AND R. M. Callaway. 1992. Root communication mechanisms and intracommunity distributions of two Mojave desert shrubs. Ecology 73: 2145-2151.

PAYNE, W. W. 1964. A re-evaluation of the genus Ambrosia (Compositae). Journal of the Arnold Arboretum 45: 401-438.

, R. W. SCORA, AND J. KunAmOTO. 1972. The volatile oils of Ambrosia (Compositae: Ambrosieae). Brittonia 24: 189-198.

Raven, P. H., D. W. Kyhos, D. E. Breedlove, and W. W. Payne. 1968. Polyploidy in Ambrosia dumosa (Compositae: Ambrosieae). Brittonia 20: 205-211.

SEAmAN, F. C., AND T. J. MABRY. 1979. Sesquiterpene lactone patterns in diploid and polyploid Ambrosia dumosa. Biochemical Systematics and Ecology 7: 7-12.

SoKal, R. R., AND F. J. RoHLF. 1981. Biometry. W. H. Freeman, San Francisco, CA. 